\title{
Leukemic Oral Manifestations and their Management
}

\author{
Carolina Favaro Francisconi ${ }^{1}$, Rogerio Jardim Caldas ${ }^{2 *}$, Lázara Joyce Oliveira \\ Martins $^{2}$, Cassia Maria Fischer Rubira ${ }^{2}$, Paulo Sergio da Silva Santos ${ }^{2}$
}

\begin{abstract}
Leukemia is the most common neoplastic disease of the white blood cells which is important as a pediatric malignancy. Oral manifestations occur frequently in leukemic patients and may present as initial evidence of the disease or its relapse. The symptoms include gingival enlargement and bleeding, oral ulceration, petechia, mucosal pallor, noma, trismus and oral infections. Oral lesions arise in both acute and chronic forms of all types of leukemia. These oral manifestations either may be the result of direct infiltration of leukemic cells (primary) or secondary to underlying thrombocytopenia, neutropenia, or impaired granulocyte function. Despite the fact that leukemia has long been known to be associated with oral lesions, the available literature on this topic consists mostly of case reports, without data summarizing the main oral changes for each type of leukemia. Therefore, the present review aimed at describing oral manifestations of all leukemia types and their dental management. This might be useful in early diagnosis, improving patient outcomes.
\end{abstract}

Keywords: Leukemia - early diagnosis - oral manifestations - dental care

Asian Pac J Cancer Prev, 17 (3), 911-915

\section{Introduction}

A number of systemic diseases including hematologic disorders have manifestations in the orofacial region (Long et al., 1998). Although non-pathognomonic, these manifestations may often represent early signs of the underlying hematopoietic disease (SklavounouAndricopoulou et al., 2002). In this context, oral complications occur frequently in leukemia and may point out the initial evidence of the disease (Aronovich and Connolly, 2008) or of its relapse (Benson et al., 2007).

Leukemia is the most common neoplastic disease of the white blood cells with an incidence of 9 cases per 100,000 population (Cotran et al., 1999). Additionally, leukemia is an ordinary malignancy accounting for about $30 \%$ of all cancers diagnosed for children aged under 15 years (Puumala et al., 2013). The current classification of leukemia is complex and a detailed description can be found in the World Health Organization Classification of Tumours of Haematopoietic and Lymphoid Tissues, published in 2001 and updated in 2008 (Campo et al., 2011). It recognizes distinct subtypes based on the cell of origin (myeloid or lymphoid) and stage of differentiation (Valera et al., 2015). So, the classification criteria of leukemia is histological and relies on (a) the similarity between the leukemic cells and normal cells (myeloid versus lymphoid) and (b) the clinical course of the disease (acute versus chronic) (Howard and Hamilton, 2008).

The oral manifestations of leukemia include gingival enlargement and bleeding, oral ulcerations, petechia and mucosal pallor (Cooper et al., 2000; da Silva Santos et al., 2010; Reenesh et al., 2012). Oral lesions arise in both acute and chronic forms of all types of leukemia. However, they are far more frequent in acute stages (Stafford et al., 1980; Greenberg and Glick, 2003). These oral manifestations either may be the result of direct infiltration of leukemic cells (primary) or secondary to underlying thrombocytopenia, neutropenia, or impaired granulocyte function (Benson et al., 2007).

Despite the fact that leukemia has been associated with oral lesions, the available literature on this topic consists mostly of case reports, without data summarizing the main oral changes for each type of leukemia. Therefore, the present review aimed at describing oral manifestations of all leukemia types and their dental management. This might be useful in early diagnosis, improving patient outcomes.

\section{Acute Myeloid Leukemia}

Acute myeloid leukemia (AML) is a relatively unusual disease, accounting for approximately $25 \%$ of all types of leukemia among adults in the western world (Deschler and Lubbert, 2006). Although the incidence of acute leukemia constitutes less than $3 \%$ of all malignancies, it is still the leading cause of death in childhood (Rubnitz et al., 2010) and represents $1.2 \%$ of cancer deaths in the United States (Jemal et al., 2002). 
It is also important to note that myeloid sarcoma (MS) is strongly associated with acute myeloid leukemia, chronic myeloproliferative diseases or myelodysplastic syndromes (Papamanthos et al., 2010). One to eight percent of patients with AML are affected by this rare extramedullary malignant tumor composed of immature myeloid cells (Papamanthos et al., 2010).

\section{Oral Manifestations of AML}

Patients with AML generally present with symptoms related to complications of pancytopenia (anemia, neutropenia, and thrombocytopenia), including weakness, and easy fatigue, infections of variable severity, and/ or hemorrhagic findings such as gingival bleeding, ecchymoses, epistaxis or menorrhagia (Dean et al., 2003). Compared to other types of leukemia, oral manifestations are ordinarily seen in AML (Hou et al., 1997).

Oral physical examination may show mucosal pallor related to anemia; spontaneous bleeding and petechial hemorrhages of gingivae, palate, tongue or lips arising from thrombocytopenia; and gingival hyperplasia caused by leukemic infiltration. Oral ulcerations are frequent and may follow either neutropenia or direct infiltration by leukemic cells. Patients may exhibit recurrent viral, bacterial and fungal infections (like herpes and candidiasis) as a consequence of immunosuppression (Stafford et al., 1980; Hou et al., 1997).

The most prevalent oral signs and symptons are gingival bleeding, oral ulceration and gingival hyperplasia (Stafford et al., 1980; Cooper et al., 2000). These may correspond to early manifestations of AML (da Silva Santos et al., 2010; Guan and Firth, 2015; Hasan et al., 2015). Particularly, gingival infiltration comprises 5\% of early complications (Williams et al., 1990). Gingival overgrowth varies in severity from minimal to complete tooth covering, impairing function and esthetics (Cooper et al., 2000).

Besides, atypical features have been observed in some cases, such as chin numbness, tooth pain and mobility, cracked lips and hemorrhagic bullae on the anterior dorsum of the tongue, buccal and labial mucosa (Dean et al., 2003). Another rare oral manifestation associated with AML is the noma-like lesion (Auluck et al., 2008). Patients with leukemia are more likely to develop noma during chemotherapy inasmuch as this can induce agranulocytosis (Brady-West et al., 1998). There are only five cases reported concerning noma or noma-like lesions in patients with hematologic malignancies in PubMED (Brady et al., 1998; Santos et al., 2011). Finally, some authors support that intraoral MS involves patients with the subtype of granulocytic origin (Xie et al., 2007).

\section{Chronic Myeloid Leukemia}

Chronic leukemias are characterized by the presence of large number of well-differentiated cells in the bone marrow, peripheral blood and tissues with a prolonged clinical course, even without therapy. On the other hand, the immature cells predominate in acute leukemias, and the untreated clinical course leads to death in months
(Greenberg and Glick, 2008).

Chronic myeloid leukemia (CML) is one of the myeloproliferative disorders most commonly seen in adults at the age between 30 and 50 years (Cotran et al., 1999). CML accounts for about $20 \%$ of all cases of leukemia. Affected patients develop hepatosplenomegaly, with massive enlargement of the spleen due to infiltration by leukemic cells. The peripheral blood shows leukocytosis with $n$ excess of neutrophils, myelocytes, and metamyeolocytes (Cotran et al., 1999).

\section{Oral Manifestations of CML}

The oral manifestations of chronic or acute leukemia often involve enlargements of the gingival and mucosal tissue from direct leukemic cell infiltration (da SilvaSantos et al., 2010). Indeed, a case report showed inflammatory cellular reactions in the oral cavity of patients with CML (Cattaneo, 1966). However, the oral involvement of granulocytic sarcoma is rare and only 38 cases have been reported in scientific literature to date (Osterne et al., 2009).

Oral sign occurs rarely and is mainly associated with the suppression of normal bone marrow in the accelerated phase of the disease, with the exception of the enlargement of gingival tissues and mucosa, a regular oral manifestation in this period (Lopes, 2009). Similarly, granulocytic sarcoma of the jaws is a rather common finding observed during the chronic phase of the disease (Castella et al., 1984). It represents a localized deposit of myeloid cells having a whitish or a green tinge color associated with the myeloperoxidase synthesis (Castella et al., 1984).

Granulocytic sarcoma was reported in a CML patient, when a physical examination revealed generalized gingival overgrowth, periodontal and apical diseases, as well as bleeding gums, involving the upper and lower jaw secondary to a CML blastic crisis. Although the diagnosis of CML had been previously established, the oral cavity biopsy was performed to confirm the tumor diagnosis (da Silva-Santos et al., 2010).

\section{Acute Lymphoblastic Leukemia}

Acute lymphoblastic leukemia (ALL) is a malignancy characterized by the uncontrolled clonal proliferation of a transformed lymphoblast with overgrowth and displacement of normal bone marrow precursors (Aronovich and Connolly, 2008). It usually comprises $97 \%$ of all types of leukemia, and $80 \%$ of subtypes of acute one, and has a male predilection (Jabbour et al., 2005). ALL represents most of the types of childhood leukemia (75\% of all newly diagnosed leukemia and $25 \%$ of all malignancies in childhood) (Yeoh et al., 2013) and 20\% of adult leukemias (Jabbour et al., 2005) with the highest incidence among people aged from 2 to 5 years followed by a second peak after the age of 50 years, presenting a bimodal distribution (Valera et al., 2015).

\section{Oral Manifestations of ALL}


Early symptoms may be associated with pancytopenia (anemia, neutropenia or thrombocytopenia), including nonspecific ones, such as fatigue, dyspnea, fever, pallor, weight loss or bleeding. Blasts may also infiltrate organs or lymph nodes, resulting in hepatosplenomegaly, lymphadenopathy or bone pain. Symptoms of testicular or central nervous system (CNS) involvement are rarely noted at diagnosis (Valera et al., 2015).

In addition, ALL may involve the lymphoid-bearing tissue of the orofacial region including the tonsils. Intraorally, mucosal pallor, gingival bleeding, or echymoses may be noted, while lymphadenopathy of the head and neck region is a consistent sign (Declerck and Vinckier, 1988). Pericoronitis may also correspond to an initial manifestation of ALL (Aronovich and Connolly, 2008). Katz and Peretz (2002) reported trismus as the first presentation of ALL in a 6-year-old boy, when intraoral examination and panoramic radiograph demonstrated no signs of infection and/or other pathology. The trismus could be explained as an intensive infiltration of leukemic cells into the deep portion of the muscles of mastication.

Several studies have reported an increased incidence of mucosal anomalies characterized by extensive ulcers, coated tongue, fetor oris, shallow papillae, tender oral mucosa and oral mucosal infections (mucositis, candidiasis, herpes simplex, varicella/zoster and cytomegalovirus) in ALL patients (Anirudhan et al., 2008).

In this context, Martini and colleagues (2013) described a rare case of multiple irregular ulcers on the mouth floor, labial mucosae and tongue, representing early signs of ALL. In this case, oral ulcerations were secondary neither to leucopenia nor to neoplastic infiltration (Martini et al., 2013). Some other cases described gingival swelling as the first manifestation of ALL (Pai et al., 2012; Silva et al., 2012). One of them showed a painless discrete swelling of fibrous consistency in the area between the upper-right central incisor and the left canine with ill-defined limits and approximately $30 \mathrm{~mm}$, leading to the relaxation of the gingival-labial sulcus (Silva et al., 2012).

\section{Chronic Lymphocytic Leukemia}

Chronic lymphocytic leukemia (CLL) is most frequent in Western countries, comprising from $25 \%$ to $35 \%$ of all types of leukemia (Richards et al., 2000; Altekruse et al., 2010), with only 5\% of oral involvement (Kemp et al., 2008). The annual incidence ranges from 5 to 15 cases per 100,000 population. Considering people aged over 80 years, the incidence exceeds 30 cases per 100,000 population a year. The median age at diagnosis is 72 years. About $10 \%$ of CLL patients are reported to be younger than 55 years of age (Eichhorst et al., 2015). CLL can be misdiagnosed because of clinical features mimicking other diseases (e.g. fibroma, periodontal disease, etc.) (Richards et al., 2000). T-cell large granular lymphocytic (T-LGL) leukemia, a specific subtype of CLL, is usually an indolent disorder with a median survival time longer than 10 years (Arvanitidou et al., 2011). The diagnosis is made by histological and immunophenotypical studies. Bone marrow biopsy allows staging the disease.

\section{Oral Manifestations of CLL}

CLL has the particular predisposition to involve the tonsillar tissues as well as other lymphoid-bearing soft tissues in the oral mucosa (Hou et al., 1997). Oral sites of CLL account for $5 \%$ of all cases. Seventeen percent of oral lesions are located in the vestibule and gingiva (Urquhart and Berg, 2001; Kemp et al., 2008). Gingival and palatal regions are regularly affected, while involvement of the alveolus and buccal vestibule is rare (Epstein et al., 2001; Urquhart and Berg, 2001; Kemp et al., 2008). Usually, oral manifestations of CLL are related to an advanced stage of a diagnosed disease, so that they can not be employed to advantage for making an early diagnosis (Alessandrini et al., 2012).

Furthermore, CLL may present as a local swelling, with or without ulceration and pain. These local symptoms may also be associated with recurrent oral bleeding (Kemp et al., 2008). Purpura and gingival bleeding secondary to thrombocytopenia may be found (Hou et al., 1997). Even though CLL-related bleeding is infrequently isolated, a rare case of recurrent epistaxis and asymptomatic intraoral swelling as the first symptoms of CLL was reported (Alessandrini et al., 2012). Isolated, intermittent, and severe nosebleeds were probably related to severe thrombocytopenia in this patient (Alessandrini et al., 2012). Palatal enlargement (Henefer et al., 1970) and gingival leukemic infiltration (Presant et al., 1973) were additionally associated with CLL.

Oral manifestations of T-LGL leukemia have been only exceptionally reported. Copete and colleagues (Copete and Sheridan, 2000) presented a case of a 74-year-old man with T-LGL leukemia, who had recurrent oral ulcerations on the labial mucosa for over a year. The presence of the ulcers was correlated to severe neutropenia and possibly attributable to infectious agents. Oral mucosal ulcers were noted in $4.6 \%$ (7/151) of patients with lymphoproliferative disorders of granular lymphocytes (Semenzato et al., 1997). Another case of a 65 -year-old woman with a twomonth history of diagnosed T-LGL leukemia presented with oral lesions, including ulcerations on the ventral tongue and soft palate as well as swollen, erythematous and ulcerated gingiva (Arvanitidou et al., 2011).

\section{Management of Leukemic Oral Manifestations}

Leukemic oral manifestations are characteristic of high-risk patients for dental treatment insofar as raised blast cell levels are found in the bone marrow and peripheral blood before the therapeutic onset (Sonis and Fazio, 1995). Thus, dental care for these patients should focus on injury prevention, local control of gingival bleeding by the elimination of biofilm, and prevention of any oral infection caused by leucopenia. Oral hygiene (brushing, use of fluoride, and noncariogenic diet) should also be emphasized throughout treatment.

The oral lesions reported in this review are summarized in Table 1 along with different managements mentioned in the scientific literature and based on our clinical experience (Katz and Peretz, 2002; da Silva Santos et al., 2010; Arvanitidou et al., 2011; Santos et al., 2011; Pai et 
Carolina Favaro Francisconi et al

Table 1. Oral Manifestations of Leukemia and their Management

\begin{tabular}{|c|c|}
\hline Oral manifestation & Management \\
\hline \multirow{2}{*}{ Gingival enlargement } & Meticulous oral hygiene by use of soft bristle tooth brush \\
\hline & Topical antiseptics (chlorhexidine $0.12 \%$ mouth rinse twice a day) \\
\hline \multirow{3}{*}{ Oral ulcerations } & Topical steroid (fluocinonide $0.05 \%$ gel) four times a day \\
\hline & Antibiotic therapy is occasionally administered to prevent bacterial infection \\
\hline & Biopsy if necessary \\
\hline \multirow{3}{*}{ Noma and noma-like lesions } & Antibiotic therapy \\
\hline & Topical antiseptics $(0.12 \%$ chlorhexidine mouth rinse twice a day) \\
\hline & Oral hygiene \\
\hline \multirow{2}{*}{ Myeloid sarcoma } & Biopsy \\
\hline & Antineoplastic therapy \\
\hline \multirow{2}{*}{ Gingival bleeding } & Meticulous oral hygiene by use of soft bristle tooth brush \\
\hline & Antifibrinolytic mouth rinse \\
\hline \multirow{4}{*}{ Oral, dental and periodontal infections } & Infection foci removal (e.g. periodontal treatment, dental extractions) \\
\hline & Topical antiseptics (chlorhexidine $0.12 \%$ mouth rinse twice a day) \\
\hline & $\begin{array}{l}\text { Antibiotics, antivirals and antifungals are administered to prevent and/or treat respec- } \\
\text { tively bacterial, virus and fungal infections }\end{array}$ \\
\hline & Granulocyte colony-stimulating factor is administered as an adjuvant \\
\hline Trismus & Physiatrics \\
\hline
\end{tabular}

al., 2012; Reenesh et al. 2012; Sepúlveda et al., 2012; Guan and Firth; 2015; Hasan et al., 2015; Zimmermann et al., 2015).

\section{Conclusions}

Usually the first signs of leukemia manifest in the mouth, and patients often search for dental care thinking that diseases are of local origin. So, the dentist plays an essential role in the early diagnosis of the hematologic disorder. It is worth to note that dentists are responsible for initiating the diagnosis in $33 \%$ of patients with acute myelomonocytic leukemia (Stafford et al., 1980). For that reason, these manifestations should be clearly recognizable, leading to a fully investigation with additional tests or a referral to a specialized professional in order to reach the final diagnosis.

\section{References}

Anirudhan D, Bakhshi S, Xess I, et al (2008). Etiology and outcome of oral mucosal lesions in children on chemotherapy for acute lymphoblastic leukemia. Indian Pediatr, 45, 47-51.

Aronovich S, Connolly TW (2008). Pericoronitis as an initial manifestation of acute lymphoblastic leukemia: a case report. $J$ Oral and Maxillofacial Surgery, 66, 804-8.

Arvanitidou I-E, Nikitakis NG, Sklavounou A (2011). Oral manifestations of T-cell large granular lymphocytic leukemia: a case report. Journal of oral \& maxillofacial Res, 2.

Auluck A, Zhang L, Desai R, et al (2008). Primary malignant melanoma of maxillary gingiva--a case report and review of the literature. J Can Dent Assoc, 74, 367-71.

Benson RE, Rodd HD, North S, et al (2007). Leukaemic infiltration of the mandible in a young girl. Int J Paediatr Dent, 17, 145-50.

Brady-West DC, Richards L, Thame J, et al (1998). Cancrum oris (noma) in a patient with acute lymphoblastic leukaemia.
A complication of chemotherapy induced neutropenia. West Indian Med J, 47, 33-4.

Campo E, Swerdlow SH, Harris NL, et al (2011). The 2008 WHO classification of lymphoid neoplasms and beyond: evolving concepts and practical applications. Blood, 117, 5019-32.

Castella A, Davey FR, Elbadawi A, et al (1984). Granulocytic sarcoma of the hard palate: report of the first case. Hum Pathol, 15, 1190-2.

Cattaneo E (1966). [Inflammatory cellular reactions in the oral cavity of patients with chronic myeloid leukemia]. Arch Stomatol, 7, 281-6.

Cooper CL, Loewen R, Shore T (2000). Gingival hyperplasia complicating acute myelomonocytic leukemia. J Canadian Dental Associat, 66, 78-9.

Copete MA, Sheridan DP (2000). Large granular lymphocyte leukemia and its association with oral neutropenic ulcerations: A case report. Oral Surg Oral Med Oral Pathol Oral Radiol Endod, 90, 474-7.

Cotran RS, Kumar V, Collins T, et al (1999). White cells and lymph nodes. In 'Robbins pathologic basis of disease', Eds 657-8

da Silva-Santos PS, Silva BS, Coracin FL, et al (2010). Granulocytic sarcoma of the oral cavity in a chronic myeloid leukemia patient: an unusual presentation. Med Oral Patol Oral Cir Bucal, 15, 350-2.

da Silva Santos PS, Fontes A, de Andrade F, et al (2010). Gingival leukemic infiltration as the first manifestation of acute myeloid leukemia. Otolaryngol Head Neck Surgery, 143, 465-6.

Dean A, Ferguson J, Marvanr E (2003). Acute leukaemia presenting as oral ulceration to a dental emergency service. Australian Dental J, 48, 195-7.

Declerck D, Vinckier F (1988). Oral complications of leukemia. Quintessence Int, 19, 575-83.

Deschler B, Lubbert M (2006). Acute myeloid leukemia: epidemiology and etiology. Cancer, 107, 2099-107.

Eichhorst B, Robak T, Montserrat E, et al (2015). Chronic lymphocytic leukaemia: ESMO Clinical Practice Guidelines for diagnosis, treatment and follow-up. Ann Oncol, 26, 
78-84.

Epstein JB, Epsteinb JD, Le ND, et al (2001). Characteristics of oral and paraoral malignant lymphoma: a population-based review of 361 cases. Oral Surg Oral Med Oral Pathol Oral Radiol Endod, 92, 519-25.

Greenberg MS, Glick M (2003). Benign tumors of the oral cavity. In 'Burket's oral medicine: Diagnosis \& Treatment', Eds PMPH-USA, 137-94

Greenberg MS, Glick M (2008). Doenças Hematológicas In 'Medicina Oral de Burket', Eds 429-53

Guan G, Firth N (2015). Oral manifestations as an early clinical sign of acute myeloid leukaemia: a case report. Australian Dental J, 60, 123-7.

Hasan S, Khan NI, Reddy LB (2015). Leukemic gingival enlargement: Report of a rare case with review of literature. Int J Appl Basic Med Res, 5, 65-7.

Henefer E, Nelson J, Beaupre E (1970). Palatal enlargement in chronic lymphocytic leukemia: report of case. J Oral Surgery, 28, 371 .

Hou GL, Huang JS, Tsai CC (1997). Analysis of oral manifestations of leukemia: a retrospective study. Oral Dis, 3, 31-8.

Howard MR, Hamilton PJ (2008). Leukaemia. In 'Haematology', Eds Philadelphia, 33-66

Jabbour EJ, Faderl S, Kantarjian HM (2005). Adult acute lymphoblastic leukemia. Mayo Clin Proc, 80, 1517-27.

Jemal A, Thomas A, Murray T, et al (2002). Cancer statistics, 2002. CA Cancer J Clin, 52, 23-47.

Katz J, Peretz B (2002). Trismus in a 6 year old child: a manifestation of leukemia? Journal of Clinical Pediatric Dentistry, 26, 337-9.

Kemp S, Gallagher G, Kabani S, et al (2008). Oral nonHodgkin's lymphoma: review of the literature and World Health Organization classification with reference to 40 cases. Oral Surg Oral Med Oral Pathol Oral Radiol Endod, 105, 194-201.

Long RG, Hlousek L, Doyle JL (1998). Oral manifestations of systemic diseases. Mt Sinai J Med, 65, 309-15.

Lopes AC (2009). Myelodysplastic syndromes In 'Tratado de clínica médica', Eds Roca, 2039-50

Martini V, Schiavone P, Bonacina R, et al (2013). NK leukemia: a rare case of oral manifestations representing the initial sign. Ann Stomatol (Roma), 4, 28.

Osterne RL, Matos-Brito RG, Alves AP, et al (2009). Oral granulocytic sarcoma: a case report. Med Oral Patol Oral Cir Bucal, 14, 232-5.

Pai A, Prasad S, Dyasanoor S (2012). Acute leukemias: a dentist's perspective. Minerva Stomatol, 61, 233-8.

Papamanthos MK, Kolokotronis AE, Skulakis HE, et al (2010). Acute myeloid leukaemia diagnosed by intra-oral myeloid sarcoma. A case report. Head Neck Pathol, 4, 132-5.

Presant CA, Safdar SH, Cherrick H (1973). Gingival leukemic infiltration in chronic lymphocytic leukemia. Oral Surgery, Oral Med, Oral Pathol, 36, 672-4.

Puumala SE, Ross JA, Aplenc R, et al (2013). Epidemiology of childhood acute myeloid leukemia. Pediatr Blood Cancer, 60, 728-33.

Reenesh M, Munishwar S, Rath SK (2012). Generalised leukaemic gingival enlargement: a case report. J Oral Maxillofac Res, 3, 5 .

Richards A, Costelloe M, Eveson J, et al (2000). Oral mucosal non-Hodgkin's lymphoma-a dangerous mimic. Oral Oncol, 36, 556-8.

Rubnitz JE, Gibson B, Smith FO (2010). Acute myeloid leukemia. Hematol Oncol Clin North Am, 24, 35-63.

Santos PSS, Neri D, Bigelli N, et al (2011). Noma-like lesion in a patient with acute promyelocytic leukemia. Rev Bras
Hematol Hemoter, 33, 321-2.

Semenzato G, Zambello R, Starkebaum G, et al (1997). The lymphoproliferative disease of granular lymphocytes: updated criteria for diagnosis. Blood, 89, 256-60.

Sepúlveda E, Brethauer U, Fernández E, et al (2012). Oral manifestations as first clinical sign of acute myeloid leukemia: report of a case. Pediatric Dentistry, 34, 418-21.

Silva BA, Siqueira CR, Castro PH, et al (2012). Oral manifestations leading to the diagnosis of acute lymphoblastic leukemia in a young girl. J Indian Soc Pedod Prev Dent, 30, 166-8.

Sklavounou-Andricopoulou A, Piperi E, Paikos S (2002). Oral and maxillofacial manifestations of malignant haemopoietic and lymphoreticular disorders: Part IIA. Haema , 5, 305-19.

Sonis ST, Fazio RC 1995. Principles and Practice of Oral Medicine, WB Saunders.

Stafford R, Sonis S, Lockhart P, et al (1980). Oral pathoses as diagnostic indicators in leukemia. Oral Surgery, Oral Med, Oral Pathol, 50, 134-9.

Urquhart A, Berg R (2001). Hodgkin's and non-Hodgkin's lymphoma of the head and neck. Laryngoscope, 111, 1565-9.

Valera MC, Noirrit-Esclassan E, Pasquet M, et al (2015). Oral complications and dental care in children with acute lymphoblastic leukaemia. J Oral Pathol Med, 44, 483-9.

Williams WJ, Beutler E, Erslev AJ, et al (1990). Hematology. In Eds McGraw Hill, New York, 243-4

Xie Z, Zhang F, Song E, et al (2007). Intraoral granulocytic sarcoma presenting as multiple maxillary and mandibular masses: a case report and literature review. Oral Surgery, Oral Med, Oral Pathol, Oral Radiol, Endodontol, 103,44-8.

Yeoh AE, Tan D, Li CK, et al (2013). Management of adult and paediatric acute lymphoblastic leukaemia in Asia: resourcestratified guidelines from the Asian Oncology Summit 2013. Lancet Oncol, 14, 508-23.

Zimmermann C, Meurer MI, Grando LJ, et al (2015). Dental treatment in patients with leukemia. J Oncol, 2015, 571739. 